LA-UR $-91-2<07$

TITLE:

A PULSED LEPTON SOURCE AT LAMPF

AUTHOA(S): $\quad$ D. HYWEL WHITE

Suamitteo to: The Proceedings of the 4th International Conference on the Intersections between Particle and Nuclear Physics, Tucson, Arizona, May 24-29, 1991

DISCLAIMER

This report was prepured as an account of work sponsored by an agency of the United States Government Neither the United States (invernment nor any agency thereof, nor any of their employees, makes any warfunty, express or implied, or ussumes any legal liability or responsi. bility for the accuracy, completeness, or usefulness of any information, uppurutus, prodtct, of process disclosed, or represents that its use would not infringe privutely owned rights. Reference herein (1) any specific commercial product, process, or service by trude name, trademark. manulacturer, or otherwise does not necessarily constitute of imply its endorsement, recom. mendation, of favoring by the United States (iovernment of uny agency thereof. The views and opinions of authors expressed herein do not necessarily state of reflect those of the linileo Situlev (jovernment or any ugency thereor.

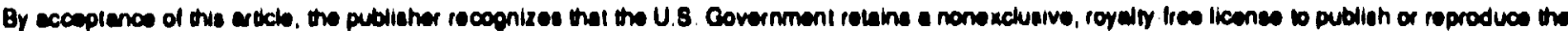
publisted form of this conitibution, of to dlow odver to do 20 . lor U S. Covemment purpoese 


\title{
A PULSED LEPTON SOURCE AT LAMPF
}

\author{
D. Hywel White \\ Los Alamos National Laboratory, Los Alamos, NM 87545
}

\begin{abstract}
A Pulsed Lepton Source is beirig considered at the LAMPF facility at Los Alamos National Laboratory. The plan for the source is described together with a description of the accelerator components and performance as they exist at present.

\section{INTRODUCTION}

In Fig. 1 is shown a schematic of the LAMPF accelerator complex. For the purposes of descripion it is convenient to divide the complex into three sections, injection, linear accelerator and the proton storage ring (PSR). At the injection area beams of protons, $\mathrm{H}^{-}$ions and polarized $\mathrm{H}^{-}$ions are produced. Beams of protons and $\mathrm{H}^{\prime}$ can be injected simultaneously although acceleration takes place at different phases of the RF. The accelerator produces pulses up to $1 \mathrm{~ms}$ in duration at $120 \mathrm{~Hz}$. $\mathrm{H}^{-}$beam is used at the PSR, but in discussing beam economics in the complex it is necessary to include the effect of other than $\mathrm{H}^{-}$beam. The linear accelerator is capable of accelerating a total instantaneous beam current of about $25 \mathrm{~mA}$ which may be divided be $x$ any of the components specified above. The linear accelerator is divided into two parts; an Alvarez section that accelerates at $201 \mathrm{MHz}$ and a side coupled cavity section that completes acceleration to $800 \mathrm{MeV}$ at $805 \mathrm{MHz}$. The $\mathrm{H}^{\prime}$ beam is split at 20 $\mathrm{Hz}$ at present in a switchyard to the beam transport labelled line D in Fig. 1. The PSR accepts beam throughout the linac macropulse and this accumulation is ejected in a single turn in a pulse of $0.25 \mu \mathrm{s}$ duration. It is this time compressed output that is relevant for PLS.
\end{abstract}

\section{INJECTION}

The injection area consists of three ion sources. The first produces protons at a peak current of about $30 \mathrm{~mA}$. After some scraping is done to produce an appropriate emittance for the lirear accelerator, and the pulse length is matched to the accelerating RF acceptance, $14 \mathrm{~mA}$ is typically accelerated. Under normal conditions, the linac has a macropulse of about $750 \mathrm{~ms}$ duration at $120 \mathrm{~Hz}$ which gives an average current of 1 $\mathrm{mA}$. The second source produces a relatively low current of $\mathrm{H}^{-}$beam $(30 \mathrm{~mA})$ with protons polarized at $\sim 50 \%$. This 'seam is stripped after acceleration simultancously with proton acceleration. An alternate $\mathrm{H}^{*}$ mode is of i.tterest to us here, presently an $\mathrm{H}^{*}$ source produces unpolarized current of $16 \mathrm{~mA}$ of which $10 \mathrm{~mA}$ can also be accelerated at the same time as protons provided the peak beam loading of $25 \mathrm{~mA}$ is not exceeded. In fact this beam is chopped near the ion source at the revolution frequency of the PSR so that the ring circumference is not fully filled and only $7 \mathrm{~mA}$ is available for PSR injection. Normal operation has unpolarized $\mathrm{H}^{\cdot}$ accelerated at $20 \mathrm{~Hz}$, the PLS proposal envisages this repetition rate being in sreased to $60 \mathrm{H} / \mathrm{z}$. At the same time it is expected that $\mathrm{H}$ source brightness can be increased so that a full charge of the proton storage ring can be accomplished in a shorter injection period. 


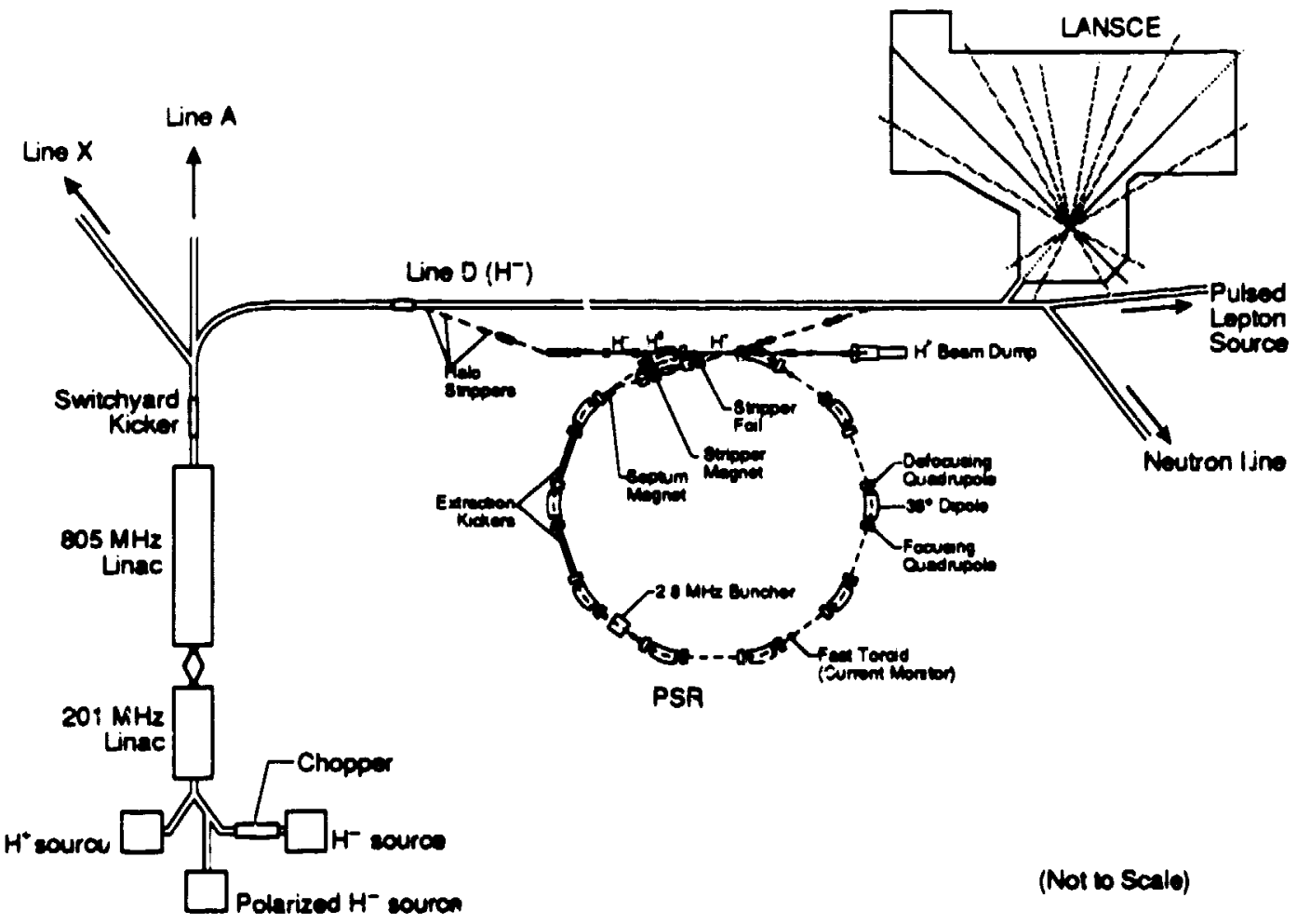

Fig. 1. A schematic of the Pulsed Lepton Source Accelerator Complex.

\section{THE LINEAR ACCELERATOR}

Acceleration is accomplished in two sections, the first for low ion velocity is an Alvarez drift tube section with $201 \mathrm{MHz}$ accelerating frequency. A transition region connects to a side coupled cavity accelerator operating at $805 \mathrm{MHz}$ which completes acceleration to $800 \mathrm{MeV}$. One in four of the high frequency $\mathrm{RF}$ buckets is filled giving an output $200 \mathrm{ps}$ wide at intervals of $5 \mathrm{~ns}$. This time structure is diluted by the energy spread in the beam when particles are allowed to dnft for significant distances. Beam from the linac is switched to a beam line marked $D$ in Fig. 1 , and transported to the PSR area.

\section{PRO'TON STORAGE RING}

In Fig. 1 the proton storage ring is also shuwn. After scraping of the halo the bear.l is transported through a high magnetic field gradient where the $H^{\circ}$ beam is stripped to $\mathrm{H}^{0}$ with nearly $100 \%$ efficiency. This heam is then injected into the ring where it is fully stipped by passing through a Carbon foil at $9(0 \%$ efficiency. The proton storage ring is operated at fixed B field; because of chopping at the injector a portion of the circumference is particle free for extraction. This particle free region is maintainrd by a $2.8-\mathrm{MHz}$ RF field. The stored beam passes through the stripping foil on a fraction of the turns determined by betatron oscillations and foil geometry. In the fin st turn, beam losses are relatively substantial after whir:h losses are proportional to the total charge accumulated from multipl." scattering in 'he stripping foil. At extraction a further loss component exists mostly due 'o the finite kick of the extraction magnet. The limiting aperture during fill is also believed to be the extraction system. With a 
peak injected current of $7 \mathrm{~mA}$ and a total fill of $3.8 \times 10^{13}$ protons the injection period must be $975 \mu \mathrm{s}$. The limitation on the amount of beam that can be stored are the losses described above that produce radinactive contamination of the ring making maintenance difficult. At present with a stored beam of $2.5 \times 10^{13}$ at $20 \mathrm{~Hz}$, the losses during accumulation are $0.6 \%$, followed by $0.1-0.2 \%$ at extraction. In order to improve this situation a number of steps may be taken which are described below. The limitation on the charge that can be accumulated comes from an instability that is present in the ring at high currents. It has been established that this threshold is reasonably stable and the PLS proposal does not involve running the ring above this current.

Low loss at extraction is accomplished in part by the gap in the charge distribution around the circumference of the ring. This gap is maintained by applied RF during storage. For minimum loss, the resulting charge distribution around the ring is not square as it is at injection but becomes almost triangular. This pulse shape is advantageous for most applications giving an apparently shorter duty factor than nominal.

\section{EXTERNAL BEAM TRANSPORT}

The extraction as described is that used to feed the neutron spallation source that is presently in operation. The only modification that is envisaged is a kicker to transfer the be Im into a PLS channel as is shown schematically in Fig. 2. It is assumed that 20 $\mathrm{Hz}$ will continue to be sent to the spallation source, a limitation on this repetition rate is given by wraparound problems with neutron time of flight. Then if $40 \mathrm{~Hz}$ is sent to PLS this will still leave $60 \mathrm{~Hz}$ for polarized protons and other uses of $\mathrm{H}$ - from the linac. A beam channel similar to that shown in Fig. 2 has been designed in some detail for a previous proposal, and an appropriately low loss system seems to be straightforward.

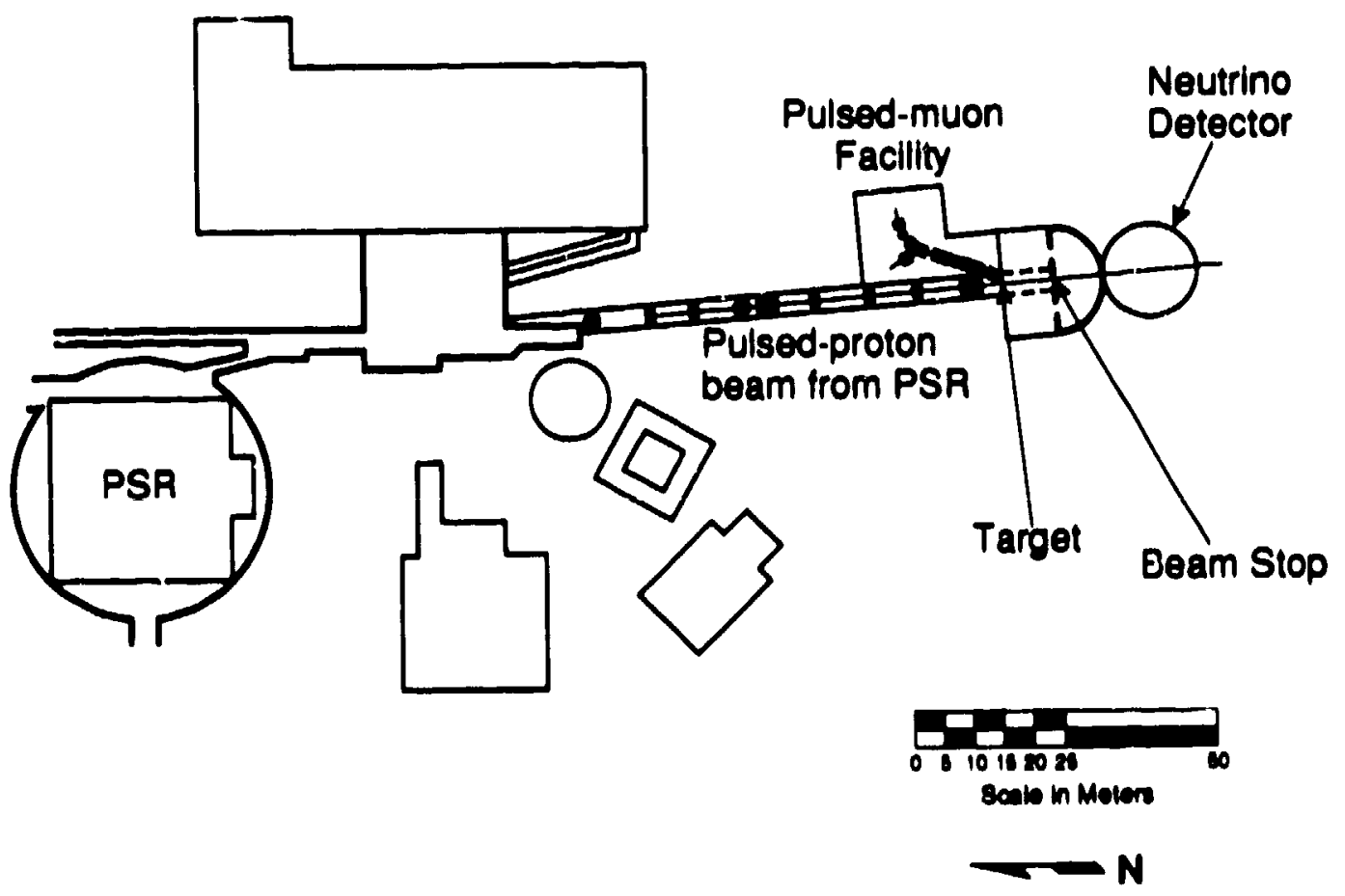

Fig. 2. The pulsed lepton source, muon and neutron facility. 


\section{TARGET AND BEAM CHANNELS}

At the target end of the transport it is envisaged that two targets would be mounted close together, one designed for muon channels, and a second designed to make the largest number of pions for neutrino generation. With a proton beam spill less than one microsecond it is straightforward to extend "old" technology and design a hom which would enhance neutrino flux as well as producing an enhancement of the flux from the pion sign that is selected. 